\title{
A Primer on Inflation: Its Conception, Its Costs, Its Consequences
}

\author{
HANS H. HELBLING and JAMES E. TURLEY
}

A

GREAT deal of public rhetoric has recently been advanced regarding our present problem of inflation. In fact, as the various price indices moved progressively higher, inflation was elevated to the position of "Public Enemy No. 1". As we crossed the bridge from single- to double-digit inflation, public discussion of inflation intensified. Concem has been expressed that that bridge might very well be bumed behind us unless steps are taken immediately to assure a return trip to price stability.

Implicit in a decision by society to seek a lower rate of inflation is some knowledge of the costs in. volved. In particular, in demonstrating a willingness to endure some temporary hardship, society decides that the cost of allowing inflation to continue unchecked exceeds the cost of pursuing a determined anti-inflation policy.

For many of us, these costs are not always readily identifiable and certainly not perfectly predictable. The purpose of this article is to discuss in general terms, without attempting to quantify, the costs and consequences of inflation. Prior to that discussion, inflation is defined and an explanation is provided of how inflationary pressures develop.

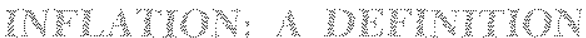

In this article inflation is defined as a continuing rise in the average level of prices. Although this definition may seem fairly straightforward and generally acceptable to all, there are a few distinguishing features which are often overlooked in its application. Specifically, there are three situations which do not necessarily fit this definition:

1) price increases of individual goods;

2) a once-and-for-all increase in the average level of prices;

3) a temporary increase in the average level of prices.

It has been particularly popular in recent times to focus on the price increases of individual goods and services and conclude, on the basis of that evidence, that inflation is ruming rampant. Individual prices neither cause nor lead to inflation, as defined above. What is missing is recognition of the fact that there are a myriad of individual prices which constitute a given average price level. ${ }^{1}$ At any point in time, there are some individual prices being affected by downward pressures, others by upward pressures. A measure of inflation is obtained only when the changes in all prices are considered. In essence, the price of one commodity may increase in a given period, but that reveals little about price changes in the whole universe of other commodities available for consumption.

A once - and - for - all jump in the average level of prices could occur as a result of some sustained random event, but a one - time rise does not affect the subsequent rate of increase in the average level of prices. Such a situation is depicted in the accompanying diagram. The trend rate of inflation is indicated in Figure $I$ by the slope of the line between $t_{n}$ and $t_{1}$. At point $t_{3}$ this trend is suddenly interrupted by some random event which, for example, causes a cutback in the supply of commodities available for consumption. The reduced supply is now consistent with a higher price level. If the price adjustment were instantaneous, we would immediately observe a higher price level but no change in the rate of price increase.

In the real world, however, the adjustment to the higher price level wolld not be instantaneous, but would probably be distributed over some time interval. This is indicated by the dotted line between $t_{1}$ and $t_{\#}$. Over this adjustment interval, the rate of change in the price level is higher than the previous trend rate of inflation. But, it is noted that the trend rate is re-established after the adjustment is completed at point $t_{2}$; that is, the higher rate of change in the price level during the adjustment perion is not a "continuing" phenomenon. Therefore, at most this

1For a discussion of one measure of changes in the price level, see Denis S. Kamosky, "A Primer on the Consumer Price Index," this Review (July 1974 ), pp. $2-7$. 


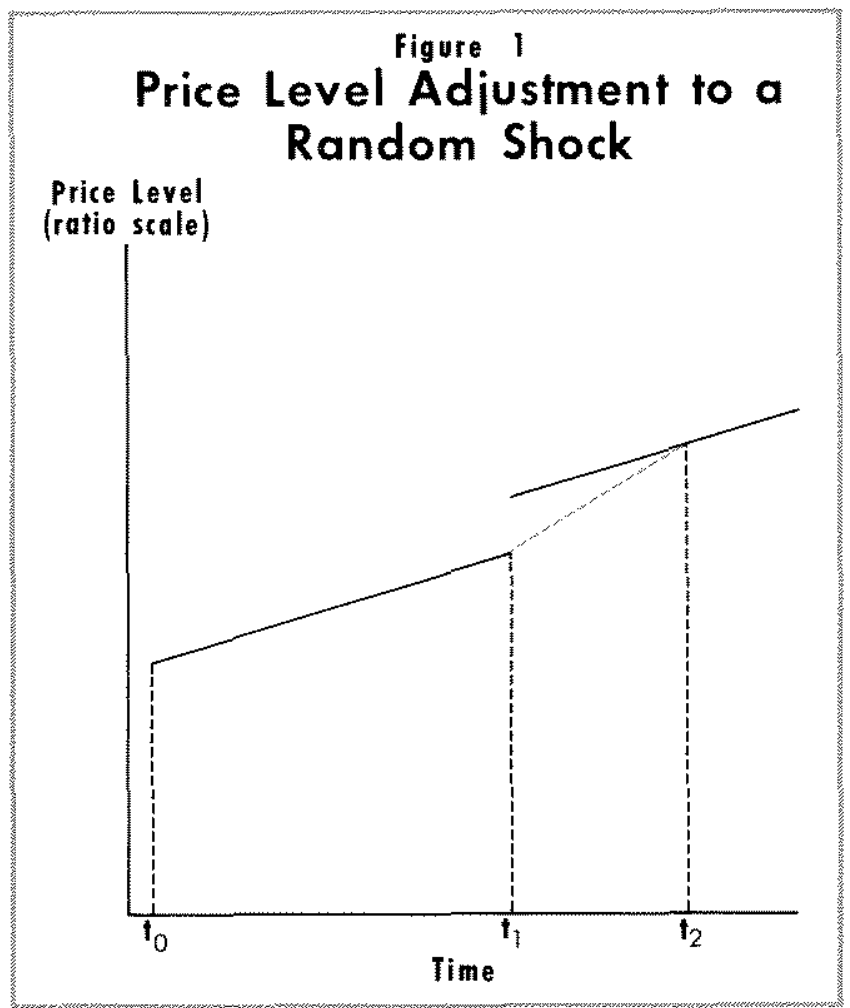

situation can be referred to as a transitory bulge in the rate of change in the price level. The jump in the price level might be attributable to the operation of "special factors"; it would not be appropriate, however, to label this jump as an increase in the rate of infation.

Price is determined by the interaction of supply and demand forces. Both of these forces can be affected by temporary events which can alter their previous relationship. In such situations prices might change, but since the event is considered temporary and likely to reverse in some later period, a label of inflation is not consistent with the definition. For example, if the harvest of some particular crop is aflected by unfavorable weather conditions, the reduced supply will be distributed among buyers by a rise in the price of the crop. This occurs because at previously existing prices total quantity supplied falls short of total quantity demanded. Even though this individual price increase may affect the average price level, such a development need not be regarded as inflationary since by its very natue "it will be sell-limiting, and . . does not in itself represent any serious policy problem." Either the supply of the same commodity will increase again in some later period, or the productive factors which are released in the production of one

"Harry G. Johnson, Exsays in Monetary Economics, $2 \mathrm{~d}$ ed. (Cambridge: Harvard University Press, 1969), p. 104. commodity will be employed to produce a new commodity or more of other existing commodities.

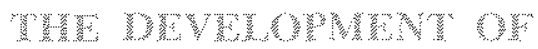

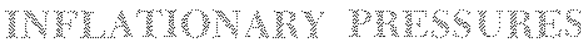

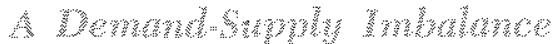

Assuming the market is permitted to function, prices always and everywhere respond to the forces of demand and supply. When the quantity of goods and services demanded at prevailing prices exceeds the available stupply of goods and services, prices tend to rise, frequently with a considerable lag; conversely, when the supply of goods and services available for consumption at prevailing prices exceeds the quantity of those goods and services demanded, prices tend to decline, also with a considerable lag.

Growth of aggregate demand for goods and services over time is influenced by economic policy actions, such as the growth of monetary aggregates and the tax and expenditure actions of the Govermment. For the most part, potential aggregate supply of goods and services tends to grow at a rate independent of stabilization policy actions. This rate of growth is detemined by factors such as increases in the labor force, trends in hours worked, and advances in technology which affect productivity and efficiency. ${ }^{3}$ An effective anti-inflation policy, therefore, would be one in which aggregate demand is permitted to expand at a rate comsistent with the expassion in aggregate supply.

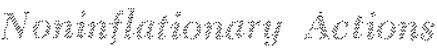

According to the analysis presented in this article, inflation (that is, continuing increases in the average level of prices) is the result of excessive growth in aggregate demand relative to aggregate supply. Since it is generally recoguzed that the ability to influence aggregate demand exists, why do inflationary conditions develop? The search for a cause ultimately leads one to look to the management of Govermment economic policies. ${ }^{\text {t }}$

:It shond be noted, however, that there are situations in which stabilization policy actions can affect the level of ontput avat able for consumption. As will be arrued later, inflation a policy-induced phenomenon) affects production efficiency ad versely, which obviously affects the available supply of good and services.

th a recent question and answer session arranged with the Office of Wonen's Programs of the White Honse, Treasury Secretary William $\mathrm{E}$. Simon made the following observations on Govermment's confribution to the current rate of price increases; "Unsomd grovernment policies inclade oun threeyear experiment with wage and price controls. . . Political 
Human nature is such that our demands for goods and services are insatiable; that is, we (individually and collectively) would prefer to consume more rather than less. The supply of resources available for consumption, however, is always less than what we would like to consume. Given that the quantity demanded must exceed the quantity supplied for inflation to occur, does this imply that inflation is a perpetual development buoyed by human nature? $\mathrm{No}$; one must distinguish between what we would like to consurne and what we are able to consume. The latter is determined by our wealth, or budget, constraint.

Our constrained demand is an important element in discussing the development of inflationary pressures. To be somewhat more specific than earlier, inflation occurs when the amount of goods and services commanded (that is, the power which economic units possess for making purchases at current prices) persistently exceeds the available supply of goods and services. Thus, the policymakers' attention should be directed at maintaining balance between command over and supply of goods and services, assuming the avoidance of inflation is regarded serionsly as an economic goal.

A visual presentation of the development of inflationary pressures is displayed in Figures II and III. Figure II displays the noninflationary actions of individuals and Government, respectively. Figure III shows the inflationary actions of the Government and the induced price level change.

In the analysis of the Government's contribution to the economic climate, the following observations are

pressures have long pat a premtum on excessive consumption. . . Monetary policier have bedn overly stimulative. And Federal bucket deficits have been spmeng intation since the early $1960 \mathrm{~s}$.

"In fact to nry way of thinking, these mosomd none: tary and fiscal policies have been the most funcamental cumses of present-day rampaging inflation." [U.S., Treasiny Depant mext, Offee of Public Afrains, Deparment of the Tronsur News, November 20,1974, p. 4.]
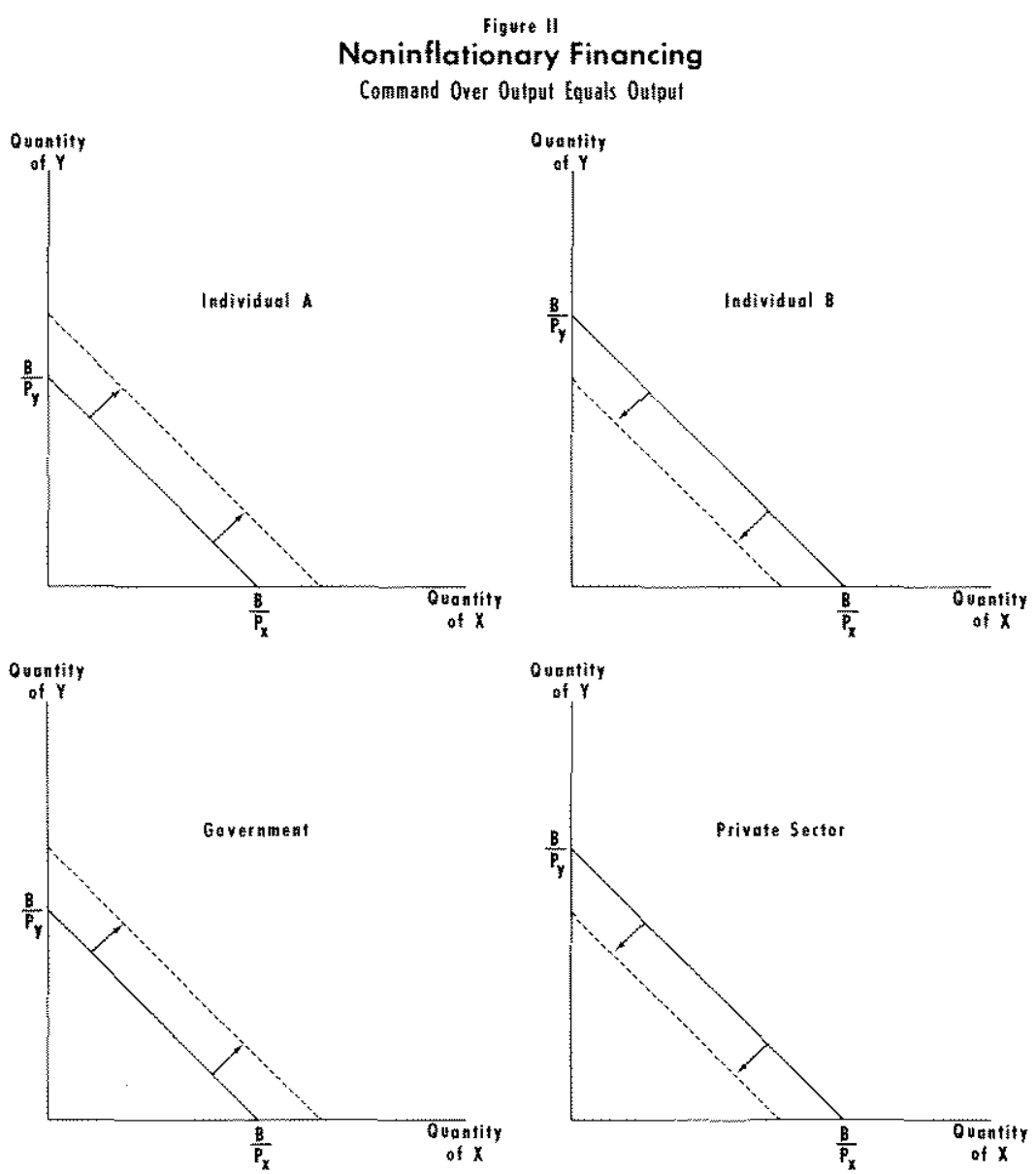

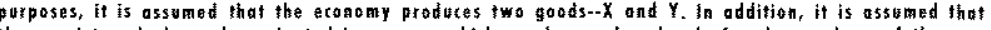

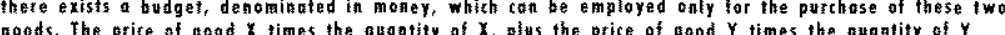

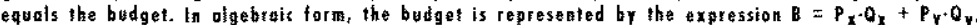
The point where the libe arosses the horinontel axis repeseats o situation where the budget is used

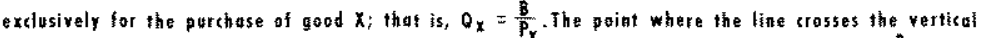
axis represents conplete extanstion of the bedget for the purctase of gaod $Y$; that is, $O_{y}=\frac{b}{F}$.

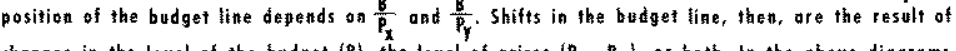

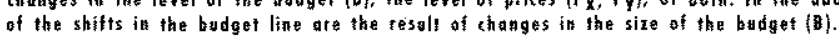

made. It is recognized that Government exists to serve the people and that the people, in turn, collectively demand services provided by the Govermment. When eforts to provide more services lead to expenditures that exceed Government's revenues, Govermment must extend its command over resources. The means by which this command is extended is a key consideration in the determination of inflationary pressures.

In the upper panel of Figure II, individual A desires to increase current consumption above that conmanded by his current income. Individual $A$ decides that borrowing is the means by which he will increase 
his share of available output. ${ }^{5}$ This is indicated by an outward shift in consumer $A^{x}$ s current budget constraint, or resource command, line. In making such a decision, individual A relinquishes claims to future consumption, to repay the loan, for the purpose of increasing current consumption. Individual B agrees to act as a lender and furnish the funds. This is indicated by a leftward shift in B's current budget constraint line. In so deciding, individual $\mathrm{B}$ foregoes a part of his current consumption for the sake of increasing future consumption. In the process A has increased his current purchasing power by the same anount as $B$ has decreased his current purchasing power. There is no change in the total command over available output, only a transfer of command from individual $\mathrm{B}$ to individual $\mathrm{A}$. No infationary pressures develop from this process.

This same noninflationary process is observed in the lower panel of Figure II. Government, for one reason or another, deems it necessary to increase its command over goods and services, as shown by an outward shift in the Government's budget constraint line." So long as this task can be accomplished by siphoning funds from the private sector (a leftward shift in the private sector's budget line), no upward pressure on prices develops. The transfer of purchasing power from the private sector to the Government takes place via explicit borrowing or tax increases.

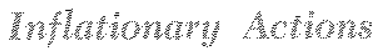

Figure III reveals the source of sustained price level increases. In this example, Government decides that money creation is the means by which it will extend its power to purchase, while the purchasing power of the private sector is initially unaffected. In the United States the process of money creation takes the following form. In order to cover expenditures that exceed current receipts, the Govermment attempts to sell securities to the public at a fixed price. If the public is not willing to purchase all of these new securities, the central bank intervenes in the securities market and purchases already outstanding Government se-

\footnotetext{
7 Another means by which a consuner can increase his con stumption of goods and services is to accept additional employment. This altemative is not comsidered here, however, because in the aggregate it involves an increase in output, violating the implicit assumption of a faxed snpply of gondis and services in the short run.

Hacteasing Govermoth command over goods and services does not necessarily mean that Govemment grows in size, that is, in tems of the amount of people it employs or the anoun of resources it comsunes. Rather, it is possible that the re distributive function of Covermment increases; that is, pur chasing power is increased for those groups of society who are effective in convincing Govermment of their "need".
}

curities from the public. In the process, the central bank gains an asset, the Government securities, and creates a liability, the money paid to the private sector which finances the purchase of the newly issued Government securities.

In effect this procedure is tantamount to printing money. The Government has more funds avalable to spend, while the purchasing power of the private sector appears to remain unchanged. Based on nominal measures, this method is appealing because it appears that no one is forced to relinquish command over output for the sake of Government's gain intially we might conchude that all of us are better off.

Such, however, is not the case. There has been an increase in the total command over resources by an amomnt equal to the quantity of money created. Since the quantity demanded now exceeds available supply at current prices, the economy generates reactions which tend to restore economic balance. The most dominant "balance-restoring" reaction is price level change. This process is indicated in Figure III which shows that increased Government spending under. written by monetary expansion results in a price level increase. This, in turn, reduces the private sector's purchasing power and restores balance between output and output commanded. If, however, the Government maintains the policy of attempting to satisfy unlimited wants by, in effect, "printing money," a continuous imbalance between supply and demand results and price level increases will persist. ${ }^{\top}$

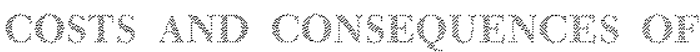 INH}

In the United States, as well as in many other countries, price stability has long been regarded as a clesirable goal. For almost a decade, however, this goal has remained elusive. One reason for its elusive quality has been the promulgation of the belief that the short-run cost of reducing the rate of inflation was greater than the cost of allowing inflation to continue unchecked. Another reason may be a lack of understanding of the causes and cures of inflation. Wage and price controls were a dramatic attempt to lower the rate of price increases while avoiding the

F Govemment-indmed deficit is not necessarily the only mears by whoh an imbalance between supply and denand at prevaling prices occurs. For example, as noted earlier, if part of the private sector desires more cument consumption, enlarged loan demand will exert upward pressure on interest rates. The centra bame in an attempt to resist this zapward pressite, may respond by expanding the nation's money supply. In this process, there is no corresponding reduction in eonsumption. in another part of the private sector. 


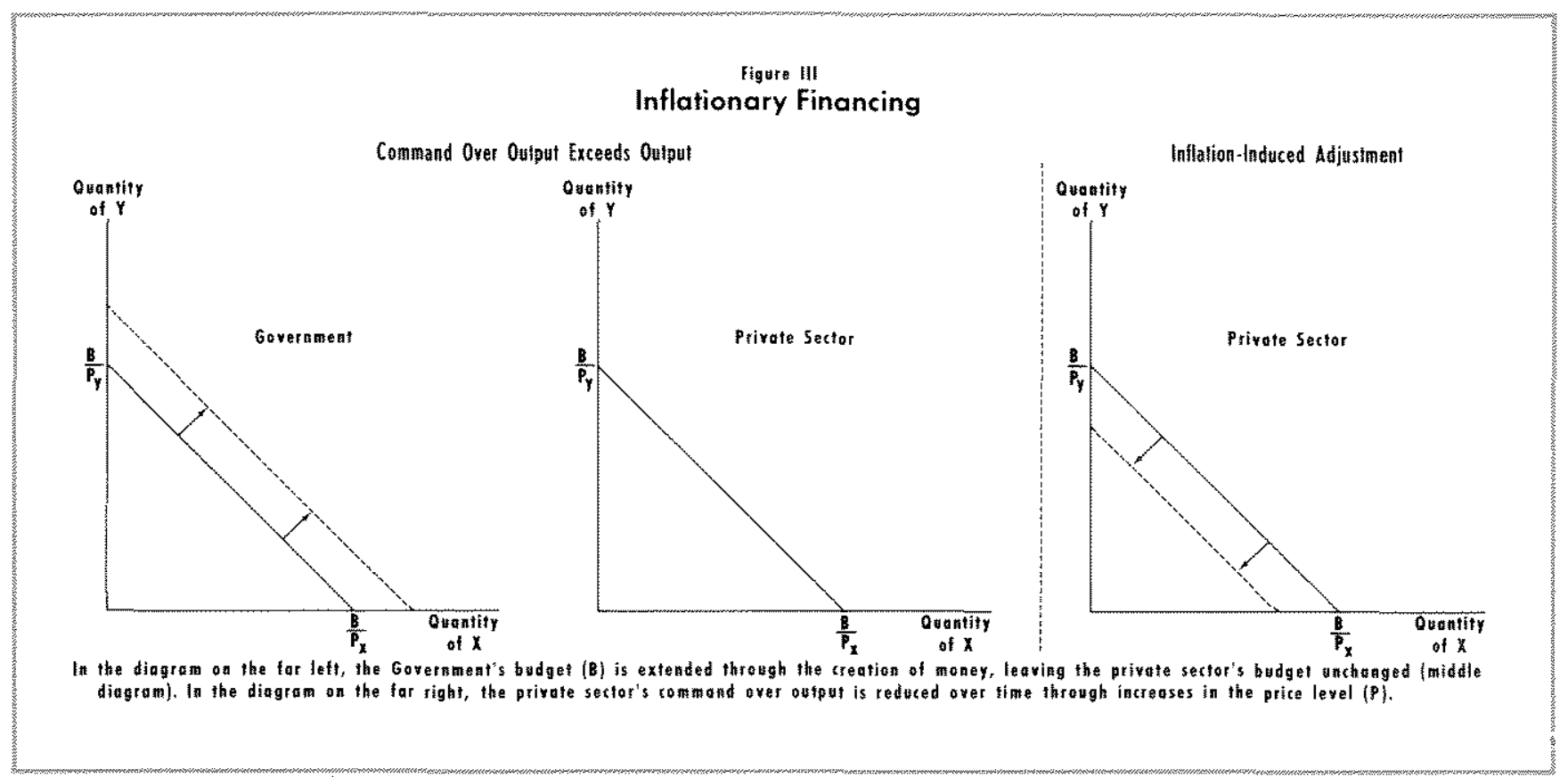

temporary costs of transition. As the "control" effort proceeded, underlying inflationary pressures mounted as a result of the maintenance of stimulative monetary and fiscal policies, and economic dislocations developed. With the realization that controls were a failure and the recognition of the costs of unchecked inflation, a re-evaluation of the inflation-price stability alternatives has been necessary.

Inflation, at any rate, generates very definite effects. These effects are related to both the transfer of wealth from one economic group to another and the allocation of resources from productive to unproductive activity. In addition, if the rate of price level increases is allowed to reach some critical point, there exists a potential for serious distortions in our system of economic as well as political organization.

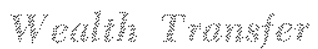

There are a variety of features which distinguish one type of inflation from another. An inflation which proceeds at a relatively steady, and hence predictable, pace has one set of effects; an inflation which proceeds by "fits and starts" and is thus not very predictable, has another set of effects. ${ }^{8}$

Holders of money lose wealth during a period of inflation, regardless of the type of inflation. Since cash balances do not earn interest, they do not rise as prices rise. Therefore, purchasing power, or com-

8Mlton Fredman, Dollars and Deficits: Living with America's Economic Problems (Englewood Cliffs: Prenticem Hall, Ine., 1968), pp. $46-50$. mand over resources, declines for those economic units whose assets are held in money form.

The generalization that inflation causes a rechanneling of wealth from creditors to debtors is incomplete unless accompanied by statements about the extent to which inflation is correctly anticipated. This effect of inflation is most easily observed in a situation where the price level changes rather sharply over relatively short time spans, catching economic units unprepared.

In such a situation, a transfer of wealth occurs when economic units engage in transactions with a less than accurate perception of the future rate of inflation. For instance, sellers may contract to sell their goods and services in the future at prices which incorporate an inadequate adjustment for inflation. It follows that the receipts from the sale of these goods and services, when adjusted for the actual rate of inflation, will not be sufficient to permit the maintenance of the seller's real standard of living. The buyer, however, has experienced an increase in real weath as the product purchased has appreciated in price by an amount greater than that anticipated at the time of contract formation. In effect, there has been a transfer of wealth from the seller to the buyer, ${ }^{9}$

${ }^{5} A$ consequence of such an inflation-induced transter of weath may be a reduction in people's willingness to fend long tem. A reduction of long-term loans is Thely to have allocative effects which could reduce economic welfare. For example, the finaneing of the $U$. $S$. housing industry is predicated on long-term loans. If average mortgages were reduced to say, ten years, a great many people would find the cost of home ownership prohibitive. 
In addition, those receiving pensions fixed in amount or those who maintain their savings in the form of fixed income assets will find that the purchasing power of these assets declines also.

In a steady, fully anticipated inflation little wealth redistribution occurs, except for those whose wealth is held in the form of money. ${ }^{10}$ Economic units expect prices to rise at some average rate and thus make a variety of economic arrangements that will adjust for the expected price rise. For example, wage contracts would include escalator clauses or would be drawn up on the basis of the average rate of inflation expected. Interest rates would include a premium based on the generally expected increase in the level of prices. As a result of near-perfect anticipation of inflation, no particular group would be forced to transfer wealth to another group because of the change in the price level. ${ }^{11}$

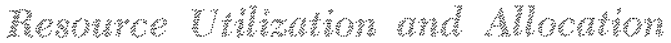

This is not to say, however, that the steady inflation is without costs. As mentioned earlier, inflation of any magnitude has the effect of making cash balances (money) an expensive item to hold. As inflation proceeds, more and more effort is devoted to keeping this expense at a minimum. By constantly scrutinizing one's cash position, valuable productive time is wasted and, in general, scarce resources are diverted from more productive activity to less productive activity due to the required monitoring of inflation. Otherwise productive members of the labor force become involved in not only figuring ont what the changes in prices and wages are likely to be, but also in hedging against those changes.

In the very process of predicting inflation, transactions and information costs are likely to increase. For example, list prices would be difficult to establish for any length of time. Firms issuing catalogs containing the prices of their products would find it difficult to continue this practice. Sales representatives would be forced to contact head offices for the most up-todate prices. In general, business planning would be frustrated because it would be necessary to constantly reassess price information. As this sort of activity becomes widespread, society in general experiences a decreased level of output available for consumption.

"Wriedman, Dollars and Deficits, p, 47.

$11 \mathrm{It}$ should be noted, however, that even in a noninflationary climate there are always changes in relatite prices taking place. Associated with such relative price changes are transfers of wealth from one group to another.

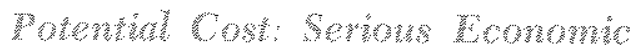

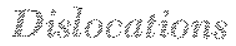

As the recently recorded rates of inflation approached and exceeded 10 percent, public concern about inftation intensified. In fact, several spokesmen, both within and outside of Government, have painted a very gloomy picture of our future in the event that inflation is not brought under control. According to this view, disruptive forces, inherent in an advanced inflationary process, may surface and cause serious distortions in our economic system. Such distortions could become severe enough to ultimately result in strong desires to change our institutions.

In all economies with organized markets, at least one commodity evolves as universally acceptable in exchange for all other commodities. "Money" is the commodity which serves this purpose. Money also provides services as a store of purchasing power and as a unit of account for recording relative values. ${ }^{12}$

During periods of inflation all of these services from money are diminished. Its function as a store of purchasing power declines, its credibility as a unit of account suffers, and its reliability as a medium of exchange is subject to greater uncertainty. As these services continue to erode as a result of accelerating inflation, there is a tendency for economie units to restructure their portfolios of real and financial assets. The restructuring takes the form of an attempt to reduce holdings of money and to increase holdings of other assets.

At some point in the inflationary process, referred to as the inflation threshold, it is generally believed that this sort of activity reaches epidemic proportions and proceeds at a very rapid pace. Such a reaction could be triggered by the recognition that the cost of holding money, especially that cost related to declining purchasing power, is so great that widespread divestment of money by individuals is pursued. Society as a whole, however, is not able to divest itself of the available stock of money; it can only circulate the existing stock of money at a faster rate. As a consequence, inflation changes from a canter to at gallop, being spurred by changes in the velocity of money circulation, completely independent of current monetary policy actions.

If inflation were to proceed to such an extent that money, as customarily defined, no longer serves as a medium of exchange, another commodity or commodi-

"For a theoretical discussion of the services of money, see
Karl Brumer and Altex $\mathrm{H}$. Mellzer, "The Uses of Money:
Money in the Theory of an Exchange Economy, The
American Economic Review (December 1971 ), pp. $784-805$. 
ties would emerge as money. Initially, however, it is not likely that any other single commodity would be accepted as a means for conducting transactions. A single commodity may eventually emerge to serve as money or what is more likely, a new form of currency wonld be introduced. During the transition, however, barter would probably become the common mode of transacting. This, then, is what is meant by serious economic distortion - barter (that is, goods and services being directly exchanged for other goods and services) becomes the dominant method of exchange. It is the consequence of a period of runaway inflation.

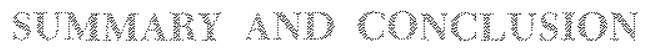

This article defined inflation as a continuing rise in the average level of prices. The cause of inflation was identified as the accommodation of unlimited wants through excessive monetary expansion. The costs of inflation include: a less than optimal resource use; an arbitrary redistribution of income in the case where inflation is less than perfectly anticipated; and to the extent that inflation is permitted to accelerate, the eventual occurrence of severe disruptions in our economic system.

In evaluating the inflation-price stability altematives, a great deal of attention has been focused on the costs of achieving price stability. Often ignored, however, is the recognition that these costs are of a short-term nature; that is, declines in production and increases in unemployment occur during the period of adjustment to a lower rate of inflation.

In an apparent willingness to accept these costs, society may demand the initiation of an anti-inflation policy. However, once the short-term costs associated with such a policy manifest themselves and inflation appears to remain unaffected, society may demand a hasty policy reversal. Failure to recognize the long lags associated with the initiation of an anti-inflation policy and the expected results of that policy results in short-run costs being incurred while the long-run benefits are not given sufficient time to materialize.

One can only hope that both the short- and longrun aspects of an anti-inflation policy will continue to be discussed. If attention is focused only on the short-term costs of reducing inflation, public sentiment toward the achievement of this goal might weaken. In such a case a high and accelerating rate of inflation is likely to plague the economy for many years to come. If, however, concern about the longterm effects of accelerating inflation remains strong, then the adoption and continuation of a determined anti-inflation policy may eventually succeed.

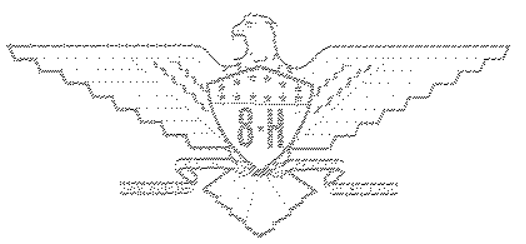

